\title{
Study on Action Skill Feature and Professional Potential of Students with Mental Retardation
}

\author{
Qi Dong1, Junming Fang ${ }^{2}$, Yaodan $\mathrm{Hao}^{3}$ \\ ${ }^{1}$ Shanghai Academy of Educational Sciences, Shanghai, China \\ ${ }^{2}$ Institute of Special Education, East China Normal University, Shanghai, China \\ ${ }^{3}$ Zhonghua Vocational School, Shanghai, China \\ Email: dongqi945@163.com, talis.bachmann@ut.ee
}

Received September $5^{\text {th }}$, 2012; revised October $4^{\text {th }}$, 2012; accepted October $18^{\text {th }}, 2012$

\begin{abstract}
A total of 217 mentally retarded people in auxiliary schools and sunshine homes took the action test implemented by self-developed testing tools. The results of statistical treatment indicates as follows: there is no significant difference in projects featuring imitation between the moderate or severe and the mild mentally retarded people; The relationship between intelligence quotient (IQ) and open action skills is obvious closer than the relationship between intelligence quotient and closed action skills; The action skills of adult mentally retarded in sunshine homes are better than those of similar IQ level in auxiliary schools. Through exploratory factor analysis of test data, we abstractly put forward three factors: ability to respond, imitate and speed, with the expectation to improve the pertinence of action skills training for the mentally retarded people. In this paper, it is stated that the moderate or severe mentally retarded can adapt themselves to certain professional positions after guided learning and training.
\end{abstract}

Keywords: Mentally Retarded; Action Skills; Professional Potential

\section{Introduction}

Long-term Education Development Plan (2010-2020) states that: we must strive to fully develop the potential and compensate for the defects of students with disabilities. It is important to train students with disabilities to live life to its full extent and give them the social awareness needed to fully integrate within society. This includes gaining self-esteem, self-confidence, independence and self-reliance. To strengthen the professional skills and employability of disabled students training to develop their professional potential, we must first understand the difficulties presented to mentally retarded people due to their action skills. As of now, China's existing research has focused primarily on studying mentally retarded students intelligence quotient and their ability to adapt. For example research has been done in researching the relationship and characteristics of mentally retarded students' IQ and adaptive behavior (Chen, Wei, \& He, 2005), as well as the analysis of mentally retarded students' IQ measurement results and educational strategies (Zheng, 2005). However there has been limited research into the characteristics of mentally retarded students' action skills and professional potential development and also a lack of tools for which to test action skills. This study aims to explore the characteristics and structure of the action skills of mentally retarded people and to explore methods and tools of which to test professional potential. These results will provide a basis at auxiliary schools for helping find the correct career path for mentally retarded students.

\section{Methods}

Firstly, by conducting questionnaires and surveys on the various department staff and teachers at Sunshine Homes, Sun- shine Factories (both are under the jurisdiction of Shanghai Disabled Persons' Federation) and all Shanghai districts' disabled persons services and schools, and other department staff and teachers; we determined that there were eight careers that could be used as typical careers for our tests. These were: delivery workers, manual workers, junior chef, dim sum chef, warehouse keeper, waiter, supermarkets, tally clerks and assembly workers. We then used these eight occupations as the basis of our analysis of work, by first finding workers of the above occupations to give a full account of their jobs and as such finding the most important skills needed for the respective jobs. We then used these findings by representing the skills in a series of motor tasks, which could then be used for testing. With these tests we could then test our sample group of mentally retarded people, with the test results being used for statistical analysis and research.

\section{Study Sample}

Sample information: A proportion of the sample were students of auxiliary school with an IQ of between 29 and 69 (IQ is measured using the Wechsler scale unless where other specified), including severe and mild mentally retarded students (Chen, 2004). The remainder of the sample was students from "Sunshine Homes" with similar IQ of between 29 and 69. The sampling method used was random sampling.

The sample consisted of 146 students in auxiliary schools and 71 students in Sunshine Homes. This consisted of 29 severely mentally retarded persons (IQ between 25 and 34), 80 moderately mentally retarded persons (IQ between 35 and 49) and 180 mildly mentally retarded persons (IQ between 50 and 69).This meant that the total sample size was 217 people. 


\section{Measurement Tools}

Through literature, research, consultation with those working in the aforementioned occupations, we designed a series of action skills tests and the production of the corresponding test tools and a computer program used to aid with the testing procedure. Test items and the corresponding tools are:

- Dovetail blocks. They consist of 3D jigsaw pieces with three or four uneven surfaces. The participants were required to assemble the building blocks into a rectangular box; the level of difficult varied depending on whether four, six, nine or fifteen jigsaw pieces were given (shown in Figure 1).

- Carron stakes. This tool is based upon the work of psychologist Carron (Carron, 1967) with an adaptation in that the test items (Pi et al., 2006) were changed. The test items became rods made of Plexiglas and plastic. The test required three different diameter rods to be removed from a Plexiglas board and inserted into another Plexiglas board, making sure the correct hole was filled by the correct sized rod (shown in Figure 2).

- Mike pipes. Test required using a doubled headed metal pipe, connecting pieces of various angles and other small linking pieces to make quadrilaterals, octagons and other geometric shapes (shown in Figure 3).

- Screen figures. Transparent Plexiglas and aluminum were combined to make a wall, which required participants to use Bakelite piece bolts, washers and nuts to fix them onto the "screen" to make a variety of geometrical figures (shown in Figure 4).

- Colourful silk flowers. The participants were asked to first make fold the silk into flower petal shapes, then use a rubber bank to make it into a silk flower (shown in Figure 5).

- Folding ribbons into flowers. The requirements were for participants to bend the nylon bands into flower petal shapes then use a stapler to steady the flower shape (shown in Figure 6).

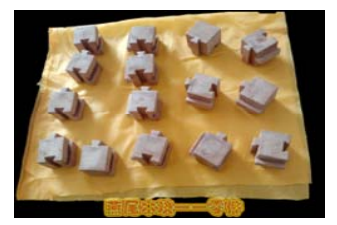

Figure 1.

Dovetail blocks.

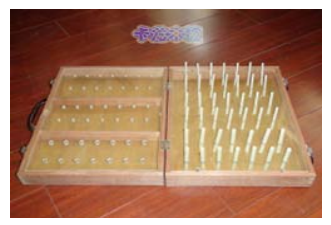

Figure 2.

Carron stakes.

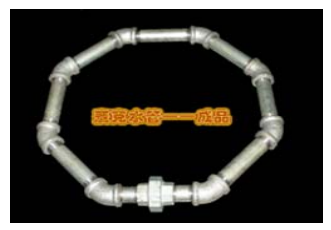

Figure 3.

Mike pipes.

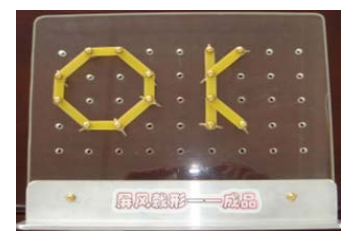

Figure 4.

Screen figures.

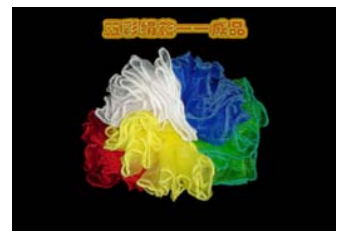

Figure 5.

Colourful silk flowers.

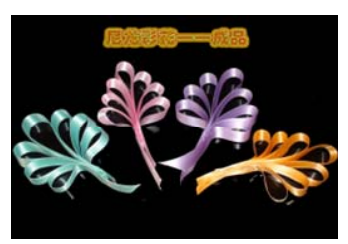

Figure 6.

Folding ribbons into flowers.

- Morgan Lantern. The device was based on the light experiments work of psychologists Shea and Morgan (Shea \& Morgan, 1979), by using a programmable controller (the core is a microcomputer)to input information into the external control button to control the intensity of the lantern. Participants were asked to press a response button responding to the correct light. The requirement was to press the correct button; otherwise the lantern would not light or would let out the wrong light intensity (shown in Figure 7).

- Colourful knots. The test required the participant to use red, green and blue ropes and knot them into a shape similar to a hair plait (shown in Figure 8).

- Linking circuits. The project required the following materials: Plexiglas panels, the wiring piles, harpoon lines, button switch, output object (light/music box/fan, etc.). The test required the participant to put the items into a circuit where if the circuit was connected correctly when the button switch was pressed, the load (light/music box/fan) and its corresponding reaction (light/sound/rotation) would occur (shown in Figure 9).

In order to achieve standardization and automation of the test control design, the testing console micro-computer (programmable controller) was used as the core to control the testing process, such as start and end of the test, automatic scoring, data transmission and records, test questions, allowing better control and coordination (shown in Figure 10). There are more depth details about the measurement tools in the book of Mentally Retarded Students Professional Potential Testing (wrote by Qi Dong), China Labor and Social Security Publishing House, published in March 2012.

\section{Research Steps}

The main steps are as follows: 


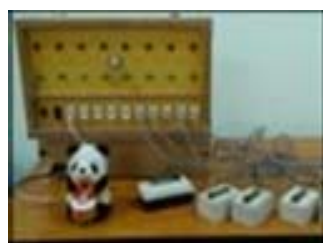

Figure 7.

Morgan Lantern.

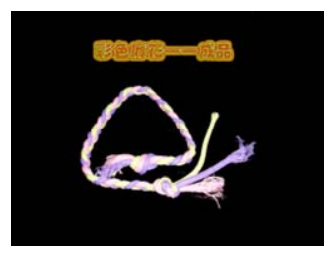

Figure 8.

Colourful Knots.

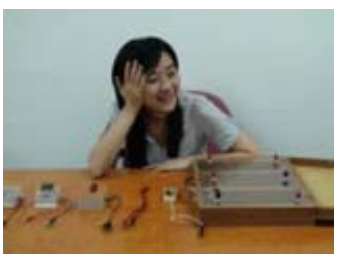

Figure 9.

Linking Circuits.

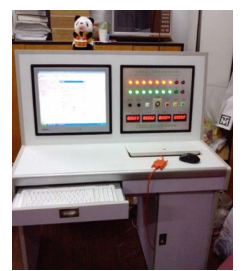

Figure 10.

The testing process controller.

First step: Field test. This was tested in a one-on-one environment with one participant and one trial staff member. At the beginning of each test, a video was played to demonstrate the testing process; participants were reminded to watch the video. They were required after the end of the video guide to complete the operation task and click on the computer program to begin the test. The main trial began as soon as the "Start" button was clicked on and once the participant completed the test, the main trial was required to press the end button to stop the timer. The main trial was then required to evaluate their performance.

Second step: Data processing. SPSS statistical software was used for the statistical analysis of test data, it allowed for analysis of results for severely/moderately mentally disabled students and mildly mentally retarded students. This led to the analysis of action skills test results of an independent two-sample T-test; leading to projections of action skills test results and IQ correlation analysis; projection of action skills test results for various factor analysis; reliability and validity analysis of the test results.

The third step is analysis. By using theories taken from psychology and special education, an in-depth study is done on the results, leading to the interpretation and summary of the results, allowing a conclusion to be formed.
The fourth step is to write a research report.

\section{Results and Analysis}

\section{Varying Degrees of Mentally Retarded Students and the Difference in Their Action Skills}

To explore in-depth the difference in the action skills of varying degrees of mentally retarded students, the statistical software SPSS was used to conduct a two-sample T-test separating moderate to severe (IQ: 25 to 49) and mildly mentally disabled (IQ > 50). The action skills test scores for the independent two-sample t-test results show that the total score, "dovetail blocks", “Carron stakes”, "Mike pipes”, "Screen figures", "Linking circuits" and "Morgan lantern", the significance level (sig. 2-tailed, two-sided test) is far less than .01 and closer to .000 , therefore leads to the rejection of the null hypothesis $\mathrm{H}_{0}$. This proves there is a significant difference in the action skills needed for these tasks in moderate to severe and mildly mentally retarded participants. However for the three projects: "Folding ribbons into flowers", "Colorful knots" and "Colorful silk flowers" the test results (as shown in Table 1) shows that each tests' significance level (sig.2-tailed, two-sided test) are respectively: .085, .693 and .604. These are all greater than .05 which means that the null hypothesis can be accepted and it can be stated that between moderate to severe mentally disabled persons and mild mentally disabled persons, there was no significant difference in score, or action ability on these three tests.

Similarly an independent two-sample T-test was used to compare and analyze severely mentally retarded persons and mild to moderate mentally retarded persons action skills scores. The results show that for the total score, dovetail building blocks, Carron stakes, Mike pipes, Screen figures, Connecting circuits and Morgan lantern scores the significance level (for the sig.2-tailed) are $.000, .000, .000, .00, .000, .000$, which is far less than .01. This leads to the rejection of the null hypothesis $\mathrm{H}_{0}$. This indicates that severe and mild to moderate mentally retarded persons in the above projects have a very significant difference in their action skills. However in "Folding ribbons into flowers", "Colorful knots" and "Colorful silk flowers", the results give significance levels (sig.2-tailed, two-sided test) of .219, .257 and .209. These are all greater than .05 which means the null hypothesis $\mathrm{H}_{0}$ should be accepted. It can be considered that severe and mild to moderate mentally retarded showed no significant difference in the action skills scores in these three projects. According to psychologists' classification, the execution of the tests and the skills needed can be predicted and divided into two types, open and closed (Pi et al., 2006). Open action skills are those where the environment is constantly changing and unpredictable, it is one where the operator cannot effectively plan for the entire task in advance. Success in open action skill tests depends on individual ability to adapt to a changing environment. Closed action skills are when the test environment is stable or predictable. Research and analysis on the operation of the above measurements and tools and test factors shows that it is not difficult to find that for dovetail building blocks, Mike pipes, Screen figures, Connecting circuits and Morgan lantern are open action skills; whilst Carron stakes, "Folding ribbons into flowers", "colorful knots" and "colorful silk flower" are examples where the test environment is fixed and are therefore closed action skills. From the above T-test results, it can be seem that mental disability affects the 
Table 1.

Independent Samples Test (sample: 217).

\begin{tabular}{|c|c|c|c|c|c|c|c|c|c|c|}
\hline \multirow{3}{*}{ Project } & \multirow{3}{*}{ Parameter } & \multicolumn{2}{|c|}{$\begin{array}{c}\text { Levene's Test for } \\
\text { Equality of Variances }\end{array}$} & \multicolumn{7}{|c|}{ t-test for Equality of Means } \\
\hline & & \multirow{2}{*}{$\mathrm{F}$} & \multirow{2}{*}{ Sig. } & \multirow{2}{*}{$\mathrm{t}$} & \multirow{2}{*}{ df } & \multirow{2}{*}{ Sig. (2-tailed) } & \multirow{2}{*}{$\begin{array}{c}\text { Mean } \\
\text { Difference }\end{array}$} & \multirow{2}{*}{$\begin{array}{l}\text { Std. Error } \\
\text { Difference }\end{array}$} & \multicolumn{2}{|c|}{ 95\% Confidence Interval of the Difference } \\
\hline & & & & & & & & & Lower & Upper \\
\hline \multirow{2}{*}{ Dovetail blocks } & $\begin{array}{l}\text { Equal variances } \\
\text { assumed }\end{array}$ & 19.075 & .000 & 5.507 & 215 & .000 & 14.487 & 2.631 & 9.302 & 19.672 \\
\hline & $\begin{array}{l}\text { Equal variances } \\
\text { not assumed }\end{array}$ & & & 5.400 & 174.795 & .000 & 14.487 & 2.683 & 9.192 & 19.782 \\
\hline \multirow{2}{*}{ Carron stakes } & $\begin{array}{l}\text { Equal variances } \\
\text { assumed }\end{array}$ & .090 & .765 & 4.308 & 215 & .000 & 12.086 & 2.806 & 6.556 & 17.617 \\
\hline & $\begin{array}{l}\text { Equal variances } \\
\text { not assumed }\end{array}$ & & & 4.314 & 213.940 & .000 & 12.086 & 2.801 & 6.564 & 17.608 \\
\hline \multirow{2}{*}{ Mike pipes } & $\begin{array}{l}\text { Equal variances } \\
\text { assumed }\end{array}$ & 9.389 & .002 & 5.408 & 215 & .000 & 12.698 & 2.348 & 8.070 & 17.325 \\
\hline & $\begin{array}{l}\text { Equal variances } \\
\text { not assumed }\end{array}$ & & & 5.348 & 195.064 & .000 & 12.698 & 2.374 & 8.015 & 17.380 \\
\hline \multirow{2}{*}{ Screen figures } & $\begin{array}{l}\text { Equal variances } \\
\text { assumed }\end{array}$ & 15.816 & .000 & 5.239 & 215 & .000 & 12.982 & 2.478 & 8.098 & 17.866 \\
\hline & $\begin{array}{l}\text { Equal variances } \\
\text { not assumed }\end{array}$ & & & 5.161 & 186.496 & .000 & 12.982 & 2.515 & 8.020 & 17.944 \\
\hline \multirow{2}{*}{ Linking Circuits } & $\begin{array}{l}\text { Equal variances } \\
\text { assumed }\end{array}$ & 11.084 & .001 & 4.750 & 215 & .000 & 13.404 & 2.822 & 7.842 & 18.966 \\
\hline & $\begin{array}{l}\text { Equal variances } \\
\text { not assumed }\end{array}$ & & & 4.694 & 193.545 & .000 & 13.404 & 2.856 & 7.772 & 19.036 \\
\hline \multirow{2}{*}{$\begin{array}{l}\text { Folding ribbons } \\
\text { into flowers }\end{array}$} & $\begin{array}{l}\text { Equal variances } \\
\text { assumed }\end{array}$ & 3.731 & .055 & 1.728 & 215 & .085 & 4.473 & 2.588 & -.629 & 9.575 \\
\hline & $\begin{array}{l}\text { Equal variances } \\
\text { not assumed }\end{array}$ & & & 1.716 & 202.905 & .088 & 4.473 & 2.607 & -.668 & 9.614 \\
\hline \multirow{2}{*}{ Colourful Knots } & $\begin{array}{l}\text { Equal variances } \\
\text { assumed }\end{array}$ & .050 & .822 & .396 & 215 & .693 & 1.155 & 2.918 & -4.596 & 6.906 \\
\hline & $\begin{array}{l}\text { Equal variances } \\
\text { not assumed }\end{array}$ & & & .395 & 209.135 & .694 & 1.155 & 2.927 & -4.616 & 6.926 \\
\hline \multirow{2}{*}{$\begin{array}{l}\text { Colourful Silk } \\
\text { flowers }\end{array}$} & $\begin{array}{l}\text { Equal variances } \\
\text { assumed }\end{array}$ & .475 & .491 & .519 & 215 & .604 & 1.248 & 2.404 & -3.490 & 5.986 \\
\hline & $\begin{array}{l}\text { Equal variances } \\
\text { not assumed }\end{array}$ & & & .516 & 205.830 & .606 & 1.248 & 2.417 & -3.518 & 6.013 \\
\hline \multirow{2}{*}{ Morgan Lantern } & $\begin{array}{l}\text { Equal variances } \\
\text { assumed }\end{array}$ & 10.613 & .001 & 8.276 & 215 & .000 & 21.619 & 2.612 & 16.470 & 26.768 \\
\hline & $\begin{array}{l}\text { Equal variances } \\
\text { not assumed }\end{array}$ & & & 8.164 & 189.704 & .000 & 21.619 & 2.648 & 16.395 & 26.843 \\
\hline \multirow{2}{*}{ score } & $\begin{array}{l}\text { Equal variances } \\
\text { assumed }\end{array}$ & 3.340 & .069 & 6.569 & 216 & .000 & 93.673 & 14.261 & 65.564 & 121.782 \\
\hline & $\begin{array}{l}\text { Equal variances } \\
\text { not assumed }\end{array}$ & & & 6.496 & 194.820 & .000 & 93.673 & 14.419 & 65.234 & 122.112 \\
\hline
\end{tabular}

ability to complete open action skills, whilst closed action skill tests are much less affected.

\section{Correlation between Mentally Retarded Students' Action Skills and IQ}

The relationship between IQ and the ability to learn action skills has been discussed and debated by many researchers, with no conclusion being reached. For example, the work of $\mathrm{M}$. L. Mattson et al. does not recognize that there is a relationship between IQ and ability to learn action skills whilst W. R. Husbend et al. suggest that there exists some sort of relationship.

Japanese psychologists Matsubara attempts to summarize the various views into two main conclusions. When the learner has normal levels of intelligence, the ability to learn small muscle action skills and intelligence shows a small positive correlation. The higher the level of intelligence and higher the academic performance; gross action skills learning and intelligence be- come practically unrelated. After going through psychologicaltraining of action skills, there is still little relationship between ability to learn and intelligence. When the learner has below normal intelligence, the small muscle and gross action skills learning and intelligence have a clear positive correlation. It also showed that the lower the intelligence, the slower the learning progress (Shao \& $\mathrm{Pi}, 1990$ ).

To gain a deeper understanding of this problem, we use the results from the 217 participants in the nine action skills tests for correlation analysis. The correlation between IQ and the total score and the seven action skills tests: dovetail building blocks, Carron stakes, Mike pipes, Screen figures, Connecting circuits and Morgan lantern had a very strong correlation, respectively: .471, .448, .332, .342, .401, .342 and .521. Of these tests Morgan lantern and IQ had the strongest correlation. This is similar to what was observed at the test site, as severely mentally disabled students showed a huge difference in their ability to complete the "Morgan lantern" test compared to mildly 
mentally retarded students. However for "Folding ribbons into flowers", "Colorful knots" and "Colorful Silk Flowers" the correlation coefficient of these three projects and IQ was .142, .044 and .074 respectively. The correlation is very small, especially for "Colorful knots" and "Colorful silk flowers" and IQ where there is almost no correlation, as shown in Table 2 below. Inspection of these test environments shows easily that there is no real relationship between these projects and IQ division or muscle size.

Therefore for those with below average IQ, it is perhaps better to judge by personal traits to decide what action skills a person has, rather than which part of the muscle type an action skill belonged to, as it has a more causal relationship to IQ. In other words, the conditions behind mentally disabled people successfully learning action skills are based upon whether an action skill is open or closed, as well as its complexity and its ability to be replicated. It matters little therefore which part of the muscles is involved in the operation.

Unlike Matsubara "big muscles, small muscles" theory, we believe that for students with intellectual disabilities, to mimic a simple closed action skill has almost no relationship to intelligence; whilst complex action skills requiring judgment and are grouped under open action skills have a clear positive link to intelligence, where the lower the IQ the slower the progress of learning such action skills.

\section{Action Skills Comparison between Mentally Retarded Students and the Sunshine Home Students}

In order to investigate the effect vocational skills training had on improving the level of action skills, the two groups (mentally retarded students and Sunshine home students) went through an independent two-sample T-test. The results showed that the average value for the students was 668.51 and 661.03 respectively. The $\mathrm{T}$ test result was .366, significance level sig was .715. This means that the null hypothesis $\left(\mathrm{H}_{0}\right)$ should be accepted and that there is no difference in the mentally retarded students and the sunshine home students in their action skills. However for IQ, the mentally retarded students had an average IQ of 45.00 whilst Sunshine Home students had an IQ of 41.96. The t-test result was 2.722 and significance level sig was .007. This means that the null hypothesis should be rejected and that there is a significant difference between mentally retarded students and Sunshine Home students IQ. To conclude, both groups have similar action skills but mentally retarded students have higher average IQ than Sunshine Home students (shown in Table 3).

\section{Factor Analysis of the Action Skills Test Data}

To further explore the relationship between the motor tests and action skills, and to summarize and interpret the test results with fewer variables, exploratory factor analysis (EFA for short) is used. Test results for the nine action skills tests and a total of 217 samples are used for factor analysis. The statistical method used is principal component analysis, factor extraction eigenvalues ( 1 as the limit), the rotation method of the biggest variance, correlation matrix to select the KMO and sphere of Bartlett's test value of .798 to meet the conditions of a factor analysis (Huang \& Guan, 2010). The program analyses and gives results for three components, the cumulative variance of $68.493 \%$, as shown in Table 4; have to factor loadings after factor analysis rotation matrix as shown in Table 5.

It can be seen from Table $\mathbf{5}$ that dovetail building blocks, Mike pipes, Screen figures, Connecting circuits and Morgan lantern make up a large composition of component 1 . However for component 2 what makes up a larger composition are "Folding ribbons into flowers", "Colorful knots" and "Colorful Silk Flowers". For component 3, the load factor is the action skills test Carron stakes.

Table 2.

Correlations (sample: 217)

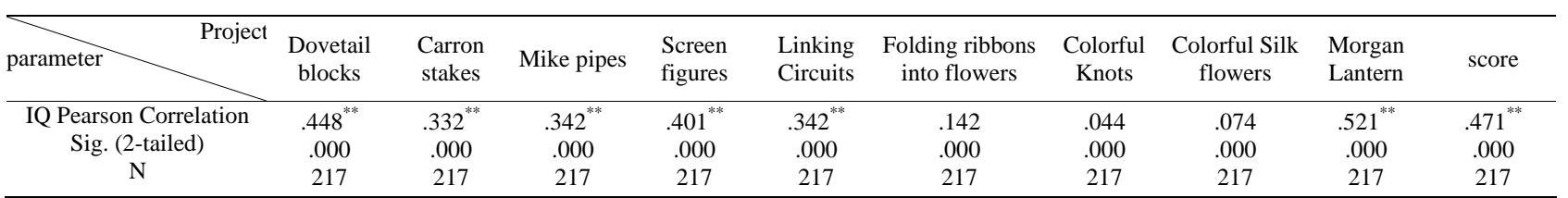

${ }^{* *}$ Correlation is significant at the .01 level (2-tailed). ${ }^{*}$ Correlation is significant at the .05 level (2-tailed).

Table 3.

Independent Samples Test(sample: 217).

\begin{tabular}{|c|c|c|c|c|c|c|c|c|c|c|}
\hline \multirow{3}{*}{ Project } & \multicolumn{4}{|c|}{$\begin{array}{c}\text { Levene’s Test for } \\
\text { Equality of Variances }\end{array}$} & \multicolumn{6}{|c|}{ t-test for Equality of Means } \\
\hline & parameter & \multirow{2}{*}{$\mathrm{F}$} & \multirow{2}{*}{ Sig. } & \multirow{2}{*}{$\mathrm{t}$} & \multirow{2}{*}{ df } & \multirow{2}{*}{ Sig. (2-tailed) } & \multirow{2}{*}{ Mean Difference } & \multirow{2}{*}{$\begin{array}{l}\text { Std. Error } \\
\text { Difference }\end{array}$} & \multicolumn{2}{|c|}{$\begin{array}{l}\text { 95\% Confidence Interval of the } \\
\text { Difference }\end{array}$} \\
\hline & & & & & & & & & Lower & Upper \\
\hline \multirow{2}{*}{ Score } & $\begin{array}{l}\text { Equal variances } \\
\text { assumed }\end{array}$ & 1.785 & .184 & .366 & 130 & .715 & 7.478 & 20.409 & -32.899 & 47.855 \\
\hline & $\begin{array}{l}\text { Equal variances } \\
\text { not assumed }\end{array}$ & & & .367 & 127.839 & .714 & 7.478 & 20.373 & -32.834 & 47.790 \\
\hline \multirow{2}{*}{ IQ } & $\begin{array}{l}\text { Equal variances } \\
\text { assumed }\end{array}$ & .059 & .809 & 2.722 & 130 & .007 & 3.042 & 1.118 & .831 & 5.254 \\
\hline & $\begin{array}{c}\text { Equal variances } \\
\text { not assumed }\end{array}$ & & & 2.733 & 128.785 & .007 & 3.042 & 1.113 & .840 & 5.244 \\
\hline
\end{tabular}


Table 4.

Total Variance Explained.

\begin{tabular}{|c|c|c|c|c|c|c|c|c|c|}
\hline \multirow{2}{*}{ Component } & \multicolumn{3}{|c|}{ Initial Eigenvalues } & \multicolumn{3}{|c|}{ Extraction Sums of Squared Loadings } & \multicolumn{3}{|c|}{ Rotation Sums of Squared Loadings } \\
\hline & Total & $\%$ of Variance & Cumulative \% & Total & $\%$ of Variance & Cumulative \% & Total & $\%$ of Variance & Cumulative \% \\
\hline 1 & 3.695 & 41.053 & 41.053 & 3.695 & 41.053 & 41.053 & 2.592 & 28.800 & 28.800 \\
\hline 2 & 1.461 & 16.238 & 57.292 & 1.461 & 16.238 & 57.292 & 2.291 & 25.451 & 54.251 \\
\hline 3 & 1.008 & 11.201 & 68.493 & 1.008 & 11.201 & 68.493 & 1.282 & 14.242 & 68.493 \\
\hline 4 & .629 & 6.985 & 75.477 & & & & & & \\
\hline 5 & .602 & 6.692 & 82.170 & & & & & & \\
\hline 6 & .501 & 5.572 & 87.741 & & & & & & \\
\hline 7 & .486 & 5.396 & 93.138 & & & & & & \\
\hline 8 & .325 & 3.610 & 96.747 & & & & & & \\
\hline 9 & 293 & 3.253 & 100.000 & & & & & & \\
\hline
\end{tabular}

Extraction Method: Principal Component Analysis.

Table 5.

Rotated Component Matrix(a).

\begin{tabular}{cccc}
\hline & \multicolumn{3}{c}{ Component } \\
\cline { 2 - 4 } & 1 & 2 & 3 \\
\hline Dovetail blocks & .644 & -.007 & .485 \\
Carron stakes & .126 & .208 & .866 \\
Mike pipes & .676 & .424 & -.087 \\
Screen figures & .766 & .321 & -.036 \\
Linking circuits & .757 & .160 & .108 \\
Folding ribbons into flowers & .168 & .761 & .335 \\
Colorful knots & .185 & .800 & -.158 \\
Colorful silk flowers & .078 & .847 & .264 \\
Morgan lantern & .690 & -.061 & .263 \\
\hline
\end{tabular}

Extraction Method: Principal Component Analysis. Rotation Method: Varimax with Kaiser Normalization. A Rotation converged in 5 iterations.

After inspection of the above mentioned action skills tests, it becomes evident that the main factor on the load factor characteristics of the larger projects are "open" action skills where its operating environment is ever changing and unpredictable. An example being the dovetail building blocks test where every time the building blocks are dismantled and the initial position of each building block is different. Due to the different combinations, a strong ability to adapt, sound judgment and flexibility are needed for the test. Another example would be the Morganlantern test, where the combination of light and dark is completely random; it is impossible to predict what the next combination will be and therefore rely on the ability to constantly adapt to changes in the boundary conditions to succeed. Mike pipes, Screen figures and connecting circuits all also reflect these key characteristics. We therefore group these tests as tests of resilience as in these tests it is the constant need to adapt that made them difficult. We name this factor the resilience factor or the "ability to respond" factor.

Factor one and two are very different and those tests that factor most for component two are based on closed action skills, tests where the operating environment remain unchanged. For example, tests such as "Folding ribbons into flowers", "Colorful knots" and "Colorful silk flowers" are testing the ability to follow the video instructions step by step in folding and creating the correct shape. There are no changes in the boundary conditions and the entire test is the based upon the ability to mimic without the need of the number of response capabilities. This means a lesser need and dependence on intelligence; we therefore group these tests as testing the ability to imitate. Accordingly, we name the factor the imitation factor or the "ability to mimic" factor.

There is also a third factor that was completely different from the two mentioned above. A test which shows a larger coefficient for this factor is the Carron stakes test, which tests the participants' ability to quickly move the stakes. This tests the participants speed and flexibility in a timed test. Therefore, this third group test participants' speed and we name this the speed factor.

Potential professional positions for the mentally retarded such as: cooks, bakers, manual laborers, tally clerks, porters and other such work, after analysis shows that these professional positions and competence to complete the job require action skills. After discussions with people with the above professions we can basically group the jobs into needing three factors: the ability to respond, the ability to imitate and speed. These three are the basic elements for professional competence. However, for different occupations the proportion of each factor and their importance is different. For example, chefs and bakers need a strong ability to imitate and a lot of speed but with less use for ability to respond to situations. Tally clerks and porters need a lot of speed and resilience whilst ability to imitate is less demanding. Manual laborers need strong resilience, the ability to mimic and moderate speed. Waiters need a strong ability to respond to quickening pace and speed but do not need a high requirement in their ability to imitate. This way, students with different aptitudes and strengths will have advan- 
tages for certain occupations due to their professional potential. On the other hand, as long as a mentally retarded person has a certain amount of all three abilities, even if they are severely mentally disabled, with repeated training it is still possible for them to take on repetitive work. Action skills tests and factor analysis provide direction to their potential career paths and training.

\section{Correlation between the Three Ability Factors and IQ}

Doing the factor analysis by the SPSS program, if you select the option of coefficients in correlation Matrix, you will obtain coefficient matrix as Table 6 shows. According to factor analysis, the coefficient matrix from which it can be obtained the capability score using the three factors: ability to respond, imitate and speed.

$\mathrm{F}_{11}=.231 \times \mathrm{S}_{11}-.134 \times \mathrm{S}_{12}+.279 \times \mathrm{S}_{13}+.332 \times \mathrm{S}_{14}+.329$ $\times \mathrm{S}_{15}-.110 \times \mathrm{S}_{16}-.016 \times \mathrm{S}_{17}-.156 \times \mathrm{S}_{18}+.304 \times \mathrm{S}_{19}$

Where: $S_{11}, S_{12} \cdots \cdots S_{19}$ are respectively the first participant's scores in the action skills tests: dovetail building blocks, Carron stakes and all the tests ending with the Morgan lantern test. $F_{11}$ is the final test score for the first participant.

$\mathrm{F}_{\mathrm{i} 1}=.231 \times \mathrm{S}_{\mathrm{i} 1}-.134 \times \mathrm{S}_{\mathrm{i} 2}+.279 \times \mathrm{S}_{\mathrm{i} 3}+.332 \times \mathrm{S}_{\mathrm{i} 4}+.329 \times$ $\mathrm{S}_{\mathrm{i} 5}-.110 \times \mathrm{S}_{\mathrm{i} 6}-.016 \times \mathrm{S}_{\mathrm{i} 7}-.156 \times \mathrm{S}_{\mathrm{i} 8}+.304 \times \mathrm{S}_{\mathrm{i} 9}$

Where for $S_{i 1}, S_{i 2} \cdots \cdots S_{i 9}$ the $i$ is the number of the participant ( 1 being the first participant) to attempt the tests: dovetail building blocks, Carron stakes ...... Morgan lantern. $\mathrm{F}_{\mathrm{i} 1}$ being similar in that $i$ is the number of the participant and being the overall test score. In a similar way test scores are worked out for $\mathrm{F}_{\mathrm{i} 2}, \mathrm{~F}_{\mathrm{i} 3}$ (factors two and three).

By using the above formulas, it is possible to work out scores for ability to respond $\left(\mathrm{F}_{\mathrm{i} 1}\right)$, ability to imitate $\left(\mathrm{F}_{\mathrm{i} 2}\right)$ and speed $\left(\mathrm{F}_{\mathrm{i} 3}\right)$ and therefore undertake analysis between the correlation between these scores and IQ. The correlation analysis results show that between ability to respond and IQ there was a strong correlation of .522 whilst ability to imitate and IQ showed a correlation score of -0.062 , the speed factor and IQ was between these two factors showing a correlation score of .307. The above studies have shown that the ability to imitate is far

Table 6.

Component Score Coefficient Matrix.

\begin{tabular}{cccc}
\hline & \multicolumn{3}{c}{ Component } \\
\cline { 2 - 4 } & 1 & 2 & 3 \\
\hline Dovetail blocks & .231 & -.170 & .326 \\
Carron stakes & -.134 & -.009 & .747 \\
Mike pipes & .279 & .120 & -.253 \\
Screen figures & .332 & .043 & -.211 \\
Linking circuits & .329 & -.057 & -.060 \\
Folding ribbons into flowers & -.110 & .339 & .189 \\
Colorful Knots & -.016 & .413 & -.270 \\
Colorful Silk flowers & -.156 & .409 & .131 \\
Morgan Lantern & .304 & -.182 & .120 \\
\hline
\end{tabular}

Extraction Method: Principal Component Analysis. Rotation Method: Varimax with Kaiser Normalization. less dependent on IQ compared to the ability to respond whilst action skills that rely on speed shows a correlation in-between the scores for respond and imitate (shown in Table 7).

\section{Reliability and Validity}

- Reliability of the test. The statistical analysis of the results shows a retest reliability of .7445; and internal consistency reliability (Cronbach's alpha) of .915 .

- Validity of the test. After testing students that have already gained vocational qualifications or professional skills test results, the results are then analyzed along with motor test results. As for the method and tool used to analyze these results, the method used is SPSS statistical software. Professional performance and validity test to test tools and methods, corresponding results obtained using the test results available for chefs and bakers show criterion-related validity of .275; whilst criterion-related validity of test results for those with a tendency towards the occupation tall clerk is .705.

Evidence supporting the effectiveness of this case. After going through the motor tests, students are placed into various vocational learning classes. Those that graduated and found work gained good feedback from their employers. This also supports the use and effectiveness of such testing. This is shown in Table 8.

\section{Main Conclusion}

There are still some issues with the testing procedure and the results. These problems are: the specialized nature of the test subject, the degree of standardization in the test being not high enough and a relatively small sample size. However, a prelimi-

nary conclusion can still be made, and below are the main aspects.

\section{Severely Mentally Retarded People are Shown to Have Better Action Skills than IQ}

Out of the 217 participants 29 are severely mentally disabled. The subjects' action skills and IQ statistics show an average IQ of 34.83 (T-scores), whilst their action skills show an average of 40.90 (T-scores). Clearly, the severely mentally retarded students have higher action skills than intelligence. Professor Chen Yunying in her article "Mentally retarded students' intellectual and adaptive behavior characteristics and relationship analysis" (Chen et al., 2005) states that "for severely mentally retarded students there exist difference between operational and verbal IQ. Overall mentally retarded students have significantly higher operational IQ than verbal.” Chen has also conducted research on vocational action skills in mildly, moderate and severely handicapped people. She concluded that there was no significant difference between their action skills and degree of mental disability $(\mathrm{F}=.641, p>.05)$. "Mentally retarded stu-

Table 7.

Correlations (sample: 217).

\begin{tabular}{|c|c|c|c|}
\hline & The resilience & The ability to imitate & The speed \\
\hline IQ Pearson Correlation & $.522^{* *}$ & -.062 & $.307^{* *}$ \\
\hline Sig. (2-tailed) & .000 & .363 & .000 \\
\hline $\mathrm{N}$ & 217 & 217 & 217 \\
\hline
\end{tabular}

${ }^{* *}$ Correlation is significant at the .01 level (2-tailed). 
Table 8.

The effectiveness case.

\begin{tabular}{|c|c|c|c|c|}
\hline Name & Result & Employer & Position & Evaluation \\
\hline Student Zhu & $\begin{array}{l}\text { Tendency to become } \\
\text { waiter }\end{array}$ & A Hotel & Cleaner & Did a great job, helpful, got on well with colleagues. \\
\hline Student Yang & $\begin{array}{l}\text { Tendency to become } \\
\text { Chef }\end{array}$ & Restaurant Catering & Kitchen Worker & $\begin{array}{l}\text { Very active and meticulous. Not afraid of working hard or being tired. } \\
\text { Respects other workers, wants to learn. }\end{array}$ \\
\hline Student Tang & $\begin{array}{l}\text { Tendency to become } \\
\text { waiter. }\end{array}$ & Hotel Chain & Waiter & Passion for work, good service, good communication with patrons \\
\hline Student Ni & $\begin{array}{l}\text { Tendency to become } \\
\text { Chef }\end{array}$ & $\begin{array}{l}\text { Hong Zhang Xing Main } \\
\text { restaurant for this group. }\end{array}$ & Kitchen worker & Good communication skills, works hard and perseveres. Wants to learn \\
\hline Student Wu & $\begin{array}{l}\text { Tendency to become } \\
\text { waiter }\end{array}$ & A hotel & Cleaner & $\begin{array}{l}\text { Qualified for job, worked carefully and meticulously. Did not blame things } \\
\text { on others faults. }\end{array}$ \\
\hline Student Zhang & $\begin{array}{l}\text { Tendency to become } \\
\text { waiter }\end{array}$ & A hotel at an airport & $\begin{array}{l}\text { Worker's canteen } \\
\quad \text { waiter }\end{array}$ & Took on heavy responsibilities at work, good interpersonal communication. \\
\hline tudent $\mathrm{He}$ & $\begin{array}{l}\text { Tendency to become } \\
\text { cook }\end{array}$ & Food and Beverage Outlet & Kitchen Worker & Did get good reviews but now undertaking military service \\
\hline
\end{tabular}

dents' Chinese Wechsler Intelligence Scale results: analysis and education countermeasures "written by a teacher at Shenzhen Yuan Ping Special School Zheng Hong, goes into details about severely mentally retarded students and the difference between their verbal and operational IQ. Hong also states that there is difference between Verbal and operational IQ and that the difference is statistically significant $(\mathrm{t}=8.939, p=.000)$ (Zheng, 2005). However, Hong's conclusion is completely different to Chen's conclusion in that she believes that severely mentally disabled students had much better verbal IQ and her data showed this by being also statistically significant (Zheng, 2005). The results of this study are generally consistent with the conclusions of the study by Professor Chen Yunying.

\section{Moderately to Severely Mentally Retarded Students Have Untapped Professional Potential}

Independent two-sample t-test show that between moderately to severely mentally retarded students and mildly mentally retarded students that for action skills tests that are simple closed tasks that relied on imitation, there is no real difference in their scores. This is shown by a correlation of -.062 , which is no real correlation. However, the correlation analysis also showed that for scores of tests that relied on speed and ability to respond and IQ showed strong correlation of .522 and .307. These statistical results show that imitation is much less dependent on IQ compared to ability to respond which requires a degree of intelligence. This means that severely mentally retarded persons should engage in work that does not require speed but should be engaged in simple tasks that require repetition and imitation. This way, their professional potential is expected to be developed.

\section{Life Experience and Training Can Also Help Improve Action Skills}

Conducting a two-sample T-test using mentally retarded students and the Sunshine Home students show that although Sunshine Home students had on average a lower IQ, there is no significant difference in their action skills. This shows that with the accumulation of life experience and also training (done at Sunshine Homes), mentally disabled persons action skills can

\section{improve.}

Individual cases from the testing process also show that the accumulation of housework and other life experiences enhances their action skills above their IQ for mentally disabled people. Participants such as Ms Sun who is ranked bottom for IQ out of the 26 students with an IQ of 35 but had an action skills test score that is tied for sixth (3 people tied). Another example is 39 year old Ms Feng who with an IQ of 40 is ranked in that same group as third lowest but who on the action skills tests have the second highest score. According to staff, these two students come from particularly difficult families which mean that heavy domestic work and the training at Sunshine Homes allow them to have action skills beyond their IQ levels. These cases prove that with a suitable amount of training and time, it is possible for mentally disabled people to improve their life skills (Chen, 2004).

\section{Summary and Recommendations}

Studies show that moderate to severely mentally disabled students show no statistically significant differences compared to mildly mentally disabled students in their ability to imitate simple closed action skills. At the same time, mentally retarded persons show different vocational potential advantages. From the test results, some mentally retarded students are suitable to become cooks and bakers and other such job while others are more suitable to become tally clerks or waiters. Also, following the accumulation of life experience and tasks such as housework which can target certain skills and train them, mentally retarded adults can still improve their action skills beyond their intelligence levels. During the test, we also learned that mentally retarded persons have a strong desire for employment, the desire to integrate into society and the want to be like everyone else in happily leading an independent life living by their own hard work. It is suggested that special vocational schools could test their students' action skills, and according to their characteristics and professional orientation to engage in targeted vocational training. This will not only increase the quality and effectiveness of the teaching for the students but also help them improve their employability leading to their integration within society. 


\section{REFERENCES}

Chen, Y. Y. (2004) The foundation of special education in China (p. 198). Beijing: Educational Science Press.

Chen, Y. Y. et al. (2005). Mentally retarded students' intellectual and adaptive behavior characteristics and relationship analysis. Chinese Special Education, 12, 27.

Chen, Y. Y. (2004). The foundation of special education in China (p. 199). Beijing: Educational Science Press.

Dong Qi's (2012) Mentally retarded students professional potential testing. Beijing: China Labor and Social Security Publishing House.

Huang, R. L., \& Guan Y. H. (2010). Statistical analysis of data-SPSS principles and application (p. 281). Beijing: Higher Education Press.
Pi, L. S. et al. (2006). Psychology of learning and education (4th ed., p. 135). Shanghai: East China Normal University Press.

Pi, L. S. et al. (2006). Psychology of learning and education (4th ed., p. 128). Shanghai: East China Normal University Press.

Shao, R. Z., \& Pi, L. S. (1990). Psychology of learning and teaching (p. 143). Shanghai: East China Normal University Press.

Zheng, H. (2005). Students with intellectual disabilities, Wechsler intelligence scale results, analysis and educational countermeasures. Journal of Chinese Special Education, 2, 42.

Zheng, H. (2005) Mentally retarded students, Wechsler intelligence scale for results analysis and educational countermeasures. Journal of Chinese Special Education, 2, 43. 